\title{
Task Interference in Prospective Memory: Adopting a Retrieval Mode and Checking for Targets
}

\author{
Melissa J. Guynn \\ New Mexico State University
}

\begin{abstract}
Embedding a prospective memory task in an ongoing activity can interfere with performance of that ongoing activity. One explanation of this task interference is that it entails (a) adopting a retrieval mode or readiness to encounter the targets that indicate when to perform the intended action and (b) checking the environment for those targets. An experiment using a new method is reported and provides evidence for these processes. On control trials, participants performed just the ongoing activity (a short-term memory task combined with a 4-choice RT task). On experimental trials, a prospective memory task (press the Enter key if certain words appear in the short-term memory task) was embedded in the ongoing activity. Evidence for adopting a retrieval mode came from finding slower RT task performance on control trials when participants had already been instructed about the prospective memory task than when they had not yet been so instructed. Evidence for target checking came from finding slower RT task performance on experimental trials when a target could appear in any one of five locations than in just one location.
\end{abstract}

\section{KEYWORDS}

prospective memory

task interference

retrieval mode

target checking

\section{INTRODUCTION}

Remembering to perform intended tasks, such as mailing a birthday card, buying pet food, or refilling a prescription, is a common element of everyday life. Typically, these prospective memory tasks must be remembered and performed amid the other activities that one does throughout the day, such as working at paid employment, parenting children, and tidying the house. Accordingly, when prospective memory tasks are implemented in the laboratory, they are embedded in an ongoing activity to simulate this demand of real-world remembering. A research participant might be asked to perform 200 trials of a lexical decision task in which they try to identify, as accurately but also as quickly as possible, whether each of a series of letter strings represents a valid word in the language. The prospective memory task might be to remember to press the Enter key if a word that refers to an animal occurs, with such words occurring on a small proportion of the trials (e.g., 5 out of 200).

Insights into the processes that support prospective memory come from inspecting prospective memory accuracy itself (e.g., the proportion of times out of 5 that a participant pressed the Enter key when an animal word occurred) and/or the accuracy and speed of responding on the ongoing activity. A common result is that performance on the ongoing activity is impaired when a prospective memory task is embedded, compared to when the ongoing activity is the only task to be

Corresponding author: Melissa J. Guynn, Department of Psychology, MSC 3452, New Mexico State University, P.O. Box 30001, Las Cruces, NM 88003-8001 Email:mguynn@nmsu.edu 
performed. Lexical decisions, for example, can be either less accurate or (more typically) slower when there is an embedded prospective memory task compared to when there is not (e.g., Scullin et al., 2010; Smith, 2003), so much so that researchers often omit analyzing accuracies and instead analyze just latencies (for correct responses only; e.g., Cohen et al., 2012; Marsh et al., 2003) on the ongoing activity. The usual interpretation of this impairment is that participants are doing something mentally to support prospective remembering that slows responding on the lexical decision task.

This impairment is generically referred to as task interference (or cost), and researchers have proposed various explanations for it. Marsh et al. (Marsh, Cook et al., 2006, Marsh et al., 2003; Hicks et al., 2005) suggested it reflects an attentional allocation policy, whereby attentional resources are diverted from the ongoing activity to support prospective remembering. Einstein and McDaniel (Einstein et al., 2005; McDaniel \& Einstein, 2000; McDaniel et al., 2004; Scullin et al., 2013) suggested it reflects strategic monitoring for the targets (e.g., the animal words) that indicate when it is appropriate to perform the intended action (e.g., press the Enter key). Smith et al. (Smith, 2003; Smith \& Bayen, 2004; Smith et al., 2017) suggested it reflects attentional processes used to prepare for a possible upcoming target and recognition processes used to identify a particular stimulus as a target. Finally, Guynn (2003, 2008; Guynn \& Underwood, 2014) suggested it reflects adopting a prospective memory retrieval mode (REMO; cf. Tulving, 1983) and checking the environment (the ongoing activity stimuli) for a target (TC).

These views are variations of the same theme, in that they all propose that task interference occurs because prospective remembering in these situations depends on limited cognitive resources that would otherwise be used for the ongoing activity. Evidence exists to support each view, and the views are not necessarily incompatible, but they may differ in their explanatory power. Moyes et al. (2019) suggested that terms such as cognitive resources, strategic monitoring, and preparatory attention are limited in their ability to explain task interference because they are "hard to map onto well-defined computational processes" (p. 84), and the authors call attention to the circularity involved with using such terms. Why does task interference occur? Because limited cognitive resources are divided between tasks. How do we know limited cognitive resources are divided between tasks? Because task interference occurs. Accordingly, Moyes et al. advise that the theoretical terms used to explain task interference be described more precisely, and they suggest that the processes of retrieval mode and target checking (REMO + TC; Guynn, 2003, 2008) are a start in that direction. The current work is part of an ongoing effort to develop methods and manipulations for exploring and understanding these constructs.

Regarding terminology, the REMO + TC view (Guynn, 2003, 2008) was proposed as an account of the processes that strategic monitoring (McDaniel \& Einstein, 2000) might comprise. However, because the involvement of retrieval mode and target checking is not necessarily incompatible with other views (e.g., they may result from a particular attentional allocation policy; Marsh et al., 2003), the theoretically more neutral term task interference (or cost) is probably more appropriate, and so that term will be used to refer to the finding that the retrieval mode and target checking are proposed to explain.

A retrieval mode is a more sustained process that can be thought of as a readiness to encounter prospective memory targets and perform the intended action. It may be context-dependent and it may fluctuate in intensity over time or trials, but it is proposed to be sustained nonetheless, in that it may not be turned on and off on a trial-by-trial basis. Target checking is a more transient process that can be thought of in terms of recognition or matching; the stimuli in the environment are attended to and a comparison is made to a prospective memory target (or targets) in mind. It is proposed to be transient in that it may be turned on and off on a trial-by-trial basis. An assumption of the REMO + TC view is that target checking cannot occur without first adopting a retrieval mode (i.e., REMO is a prerequisite for TC). Another assumption is that it is possible to adopt and maintain a retrieval mode without target checking. Whenever prospective memory succeeds in the absence of task interference, the assumption is that spontaneous retrieval supported target detection (Scullin et al., 2013).

An early experiment was conducted to explore the involvement of these processes (Guynn, 2003). It was modeled after the first published laboratory experiment on prospective memory, in which the ongoing activity involved participants performing a series of shortterm memory trials (Einstein \& McDaniel, 1990). On each trial, five words were presented briefly for study and then disappeared for recall. The embedded prospective memory task was to press the Enter key if a particular word appeared. With this ongoing activity, interference from the prospective memory task would appear as decreased shortterm memory accuracy compared to a control condition in which no prospective memory task was embedded. Latency would not be relevant here because of the nonspeeded verbal nature of the response. However, accuracy is typically a less sensitive measure than is RT, and so a task was added for which RTs could be recorded to increase the sensitivity to detect task interference. Specifically, a 4-choice RT task was added, modeled after that used by Craik et al. (1996) in their study of long-term retrospective memory (see Reitman, 1971, 1974, for application of a similar method to short-term retrospective memory). For this 4-choice RT task, four positions were displayed horizontally on the computer screen, just above the five short-term memory words. A keyboard key (also arranged horizontally) was assigned to each asterisk position. At the start of the trial, a set of three (to ensure visibility) asterisks appeared randomly in one of the four positions. After a participant pressed a key to indicate the location, the set of asterisks moved to another random location for another key press. Accuracies and RTs (latencies) for the key presses were recorded.

Participants performed significantly worse on the RT task on experimental trials (i.e., when there was an embedded prospective memory task) than on control trials (i.e., when there was no embedded prospective memory task); that is, there was task interference (Guynn, 2003). Specific evidence for the retrieval mode and target checking was provided by the fact that the degree of impairment on experimental trials relative to control trials depended on whether the trial types 
alternated or were blocked. Performance on control trials was worse when the trial types alternated than when they were blocked (such that there was less impairment on control trials compared to experimental trials when the trial types alternated than when they were blocked). This suggested that some additional mental process was occurring on alternating control trials but not on blocked control trials.

The results were interpreted in terms of the REMO + TC view (Guynn, 2003). Specifically, performance was worst on experimental trials because participants adopted a retrieval mode and checked for targets. Performance was best on control trials that were blocked because participants neither adopted a retrieval mode nor checked for targets. Performance was intermediate on control trials that alternated with experimental trials because participants were in a retrieval mode (because every alternate trial was an experimental trial and could feature a target) but did not check for targets on these trials. In other words, performance was worst when both processes were operating (experimental trials), intermediate when just one process (REMO) was operating (control trials that alternated with experimental trials), and best when neither process was operating (control trials that were blocked). These results were the first published evidence for the REMO + TC view (Guynn, 2003). Subsequent research has used similar types of manipulations and the results have also been interpreted as providing evidence for one or both processes (Ball \& Bugg, 2018b; Ball et al., 2020; Cohen et al., 2012; Lourenço \& Maylor, 2014; Lourenço et al., 2013; Marsh, Cook et al., 2006).

A different method to explore the involvement of target checking and retrieval mode has also been introduced but not yet published (Guynn \& Underwood, 2014). In this 4-quadrant paradigm, using lexical decision as the ongoing activity, letter strings are presented randomly in the four quadrants of the computer screen, but participants are told that a prospective memory target will only ever appear in one particular quadrant (counterbalanced across participants). Thus, performance can be compared across (a) the average of all four quadrants on control trials, (b) the average of the three non-target quadrants on experimental trials, and (c) the target quadrant on experimental trials. Note that both targets and nontargets appear in the target quadrant, but a target never appears in any other quadrant. Neither a retrieval mode nor target checking should be operating on control trials. A retrieval mode should be operating on experimental trials, but target checking should be operating only on target quadrant trials. Thus, an estimate of retrieval mode can be obtained by comparing (a) and (b), and an estimate of target checking can be obtained by comparing (b) and (c). A somewhat similar manipulation of target location has been used subsequently and the results also interpreted in terms of the REMO + TC view (Ball \& Bugg, 2018a; Bugg \& Ball, 2017).

According to Moyes et al. (2019), "despite the clear conceptual distinction between these two forms of monitoring process [retrieval mode and target checking], they are hard to distinguish empirically" and ".. it is hard to unambiguously identify a behavioral signature of one or the other process" (p. 84). The studies mentioned above have provided a good start toward identifying behavioral signatures of these processes. Evidence has come from intermixing and/or blocking trials where neither, both, or just one of the processes would be expected to be operating, and inferences about processes have been made on the basis of differential performance on these different trial types. The goal of the current study was to evaluate a different method for distinguishing these processes empirically and identifying their behavioral signatures. Potential advantages of this new method are suggested in the Discussion section.

The current experiment was modeled after that of Einstein and McDaniel (1990), and thus, it was similar to that used in some of the earliest work on task interference in prospective memory (Guynn, 2003; Kliegel et al., 2001, 2004). A prospective memory task was embedded in an ongoing short-term memory task, and the prospective memory task was to press a key if a target word ever appeared as one of the words in a short-term memory trial. A 4-choice RT task was also used to index the cognitive resource demands of the prospective memory task (i.e., task interference). Depending on how participants allocate their limited cognitive resources (e.g., Navon \& Gopher, 1979), task interference could be manifested as decreased accuracy on the short-term memory task, decreased accuracy on the RT task, or increased latency on the RT task. Impairment would not necessarily be expected on every dependent measure, but task interference would be implicated by impairment on any measure that was not offset by enhancement on another. For reasons stated above, any impairment was expected primarily to be revealed in RT task latencies.

The approach to seeking evidence for a retrieval mode was to create a situation where a retrieval mode, but not target checking, would be operating. In this situation, any significant task interference would provide evidence of adopting a retrieval mode. To create this situation, during control trials (where there was no embedded prospective memory task), one group of participants had not yet been instructed about the prospective memory task, and one group of participants had already been so instructed. Participants should not check for the targets during control trials, but if they adopt a retrieval mode upon receiving the prospective memory instructions, then performance during control trials should be worse for participants who have already been so instructed. If participants do not adopt a retrieval mode upon receiving the prospective memory instructions, then performance during control trials should not be affected by this manipulation.

The approach to revealing evidence of target checking was to manipulate a variable that should affect target checking but not adopting a retrieval mode. If the amount of task interference is affected by the manipulation, then the implication would be that target checking is operating. To create this situation, during one set of experimental trials, participants were informed that targets could appear as any one of the five words in a short-term memory trial, and during another set, participants were informed that targets could appear as just the first word. If participants check for the targets, then performance during experimental trials should be worse when participants are informed that targets could appear in any one of five possible locations. If participants do not check for the targets, then performance during experimental trials should not be affected by this manipulation. 


\section{METHOD}

\section{Design and Participants}

Simultaneous within-subjects and mixed designs were used. The within-subjects design was used to explore target checking and the mixed design was used to explore adopting a retrieval mode. For the within-subjects design, trial type was varied at three levels. On control trials (CON), participants performed the RT task and the short-term memory task. On 5-location experimental trials (EXP-5), participants performed the RT task, the short-term memory task, and the prospective memory task, and targets could be presented as any one of the five words in a short-term memory trial (and participants were informed of this). On 1-location experimental trials (EXP-1), participants also performed all three tasks, but targets could be presented as just the first word in a short-term memory trial (and participants were informed of this). Forty-eight participants contributed data to the within-subjects design, and the order of the three conditions was counterbalanced such that eight participants performed each possible order of the three trial types (see Appendix A for a table depicting these treatment and counterbalancing conditions).

Thus, among these 48 participants, 8 performed control trials followed by 5 -location experimental trials and then 1-location experimental trials, and 8 performed control trials followed by 1-location experimental trials and then 5-location experimental trials. For the mixed design, these 16 participants were compared to another group of 16 participants who also performed the control trials first (with the two types of experimental trials counterbalanced). For this mixed design, prospective memory instruction time was varied at two levels. For the "instructions-before" participants (the 16 who also contributed data to the within-subjects design), participants were instructed about the prospective memory task before they performed the control trials. For the "instructions-after" participants (the 16 who did not contribute data to the within-subjects design), participants were instructed about the prospective memory task after they performed the control trials (see Appendix B for a table depicting these treatment and counterbalancing conditions).

In all, there were 64 participants, with 16 contributing data to both designs, 32 to just the within-subjects design, and 16 to just the mixed design. The participants were undergraduates enrolled in a psychology course at New Mexico State University who participated in partial fulfillment of a course requirement or for extra credit.

\section{Materials}

Nontarget stimuli for the short-term memory trials were 412 one- and two-syllable common nouns selected from Clusters 6, 7, and 8 of the Toglia and Battig (1978) norms. For the test trials, 356 words from the norms (plus 4 targets) were arranged into 72 trials ( 12 blocks of 6 trials). Five words were selected randomly without replacement for each trial, with no more than three 2 -syllable words in a trial. A different target (for half the participants, "pear," "lemon," "peach," "cherry," "tangerine," or "apple;" for half the participants, "mouth," "foot," "nose," "hand," "leg," or "head") appeared in 4 of the 48 experimental trials (two 5-location trials and two 1-location trials). For practice trials, 60 words were arranged into two blocks of six trials. One block was used for practicing the short-term memory task alone, and one block was used for practicing the short-term memory and RT tasks together.

\section{Procedure}

Participants were tested individually and the experiment lasted about an hour. Because the constellation of tasks was complex, participants were given practice trials to insure they could perform the tasks before they began the test trials.

Participants first practiced the RT task, in which a set of three asterisks appeared in one of four positions near the center of the computer screen. Participants had to press the " $z$ " key if asterisks appeared in the first position (near the left center of the screen), the " $x$ " key if asterisks appeared in the second position (to the right of the first position), the " $n$ " key if asterisks appeared in the third position (to the right of the second position), and the " $m$ " key if asterisks appeared in the fourth position (to the right of the third position). As soon as a participant pressed a key, the asterisks moved to another position at random. Participants used the first two fingers of each hand and tried to press the keys as quickly and accurately as possible. For each of six trials, asterisks were presented upon a key press, for $9.5 \mathrm{~s}$.

Participants next practiced the short-term memory task. For each of six trials, five words appeared in a row near the center of the computer screen for $5 \mathrm{~s}$ and participants studied the words. Then the words disappeared for $4.5 \mathrm{~s}$ and participants tried to recall the words, out loud and in order. Participants then practiced the RT task and the short-term memory task together. The asterisk positions were centered above the words, and participants pressed the keys corresponding to the asterisks while studying and recalling the words, for two blocks of six trials.

Consistent with prior research (e.g., Guynn, 2003; Kliegel et al., 2001; Smith, 2003), and because the interest was in producing task interference, no delay was interpolated between the practice trials and the test trials. Following the practice trials, participants performed three sets of 24 trials each, with the 24 trials arranged into four blocks of six trials each. There was a $10 \mathrm{~s}$ rest break at the end of each block. At the beginning of each set of 24 trials, participants were instructed which tasks to perform and, when appropriate, whether the targets could appear as any one of the five words or as just the first word in a short-term memory trial. For the prospective memory task, half the participants were instructed to press the Enter key if they ever saw "a word that is a fruit," and half the participants were instructed to press the Enter key if they ever saw "a word that is a part of the human body."

All participants performed the same 72 trials in the same order (except for the positions of the trials containing the targets). In the $48 \mathrm{ex}-$ perimental trials, a different fruit or body part word appeared in each of the first and third blocks (between Trials 2 and 5) of one 24-trial set, and in each of the second and fourth blocks (between Trials 2 and 5) of one 24-trial set. Across conditions and participants, targets appeared equally often in the first and third blocks of one set and in the second 
and fourth blocks of another set. Targets appeared once each in Trials $2,3,4$, and 5 for each participant. In the 1-location condition, the targets appeared as the first word in a short-term memory trial, and in the 5-location condition, the targets appeared as any of the five words in a short-term memory trial.

\section{RESULTS}

All reported effects were significant at least at a .05 level unless otherwise indicated. The mean RTs for correct asterisk key presses, the mean proportions of correct asterisk key presses, and the mean proportions of correct short-term memory responses were inspected for task interference. The target trials were not included in these analyses. Also, following Anderson et al. (1998), asterisk key presses with latencies of less than $100 \mathrm{~ms}$ were excluded from the analyses. The results for the mixed design conditions (to be inspected for adopting a retrieval mode) are presented in Table 1 and the results for the within-subjects conditions (to be inspected for target checking) are presented in Table 2. The results are first evaluated for evidence of task interference in general, and then for adopting a retrieval mode and target checking specifically. Then, the prospective memory results are presented.

\section{Task Interference}

The first question concerned whether participants performed worse on experimental trials than control trials (i.e., whether there was task interference). A one-way within-subjects omnibus analysis of variance (ANOVA) was conducted using the 48 participants in the within-subjects design because their trial types were completely counterbalanced. RT task latency was the dependent variable and trial type (control, 1-location experimental, 5-location experimental) was the independent variable. The ANOVA revealed a significant effect of trial type, $F(2,94)=14.60, \mathrm{MSE}=21049.89, p<.0001, \eta^{2}=.24$. A planned comparison revealed significantly worse performance on experimental trials than control trials, $F(1,94)=17.01$, MSE $=21049.89, p<.00009$, $\eta^{2}=.15$, indicating that the prospective memory task interfered with (i.e., slowed) performance of the RT task. The comparable omnibus ANOVAs with RT task accuracy and short-term memory accuracy as dependent variables did not reveal significant effects of trial type, $F(2$, $94)=.51, \mathrm{MSE}=.003, p=.61, \eta^{2}=.01$, and $F(2,94)=.90, \mathrm{MSE}=.003$, $p=.42, \eta^{2}=.02$, respectively.

\section{Adopting a Retrieval Mode}

The second question concerned whether participants performed worse on control trials when they had already been instructed about the prospective memory task than when they had not yet been so instructed, which would provide evidence for adopting a retrieval mode. A planned comparison was conducted to test this prediction. Instruction time (before control trials, after control trials) was the between-subjects independent variable and RT task latency was the dependent variable. The comparison revealed significantly worse performance on control trials in the instructions-before condition than in the instructions-after condition, $F(1,60)=5.47, \mathrm{MSE}=25628.37$, $p<.03, \eta^{2}=.01$, consistent with the idea that the instructions-before participants adopted a retrieval mode during control trials. In contrast, performance between the instructions-before and instructions-after conditions was not significantly different on either the 1-location or the 5-location experimental trials, $F(1,60)=2.34, \mathrm{MSE}=25628.37, p$ $=.14, \eta^{2}=.005$, and $F(1,60)=1.84$, MSE $=25628.37, p=.19, \eta^{2}=.004$, respectively, when both groups had presumably adopted a retrieval mode.

The comparable planned comparisons with RT task accuracy as the dependent variable showed no significant difference between the instructions-before and instructions-after conditions on control trials, 1-location experimental trials, or 5-location experimental trials, $F(1$, $60)=.02, \mathrm{MSE}=.001, p=.89, \eta^{2}=.000001 ; F(1,60)=.56, \mathrm{MSE}=$ $.001, p=.46, \eta^{2}=000001$; and $F(1,60)=.01, \mathrm{MSE}=.001, p=.93, \eta^{2}=$ 000001 , respectively. The comparable planned comparison with shortterm memory accuracy as the dependent variable showed no significant difference between the instructions-before and instructions-after conditions on control trials, $F(1,60)=1.07$, MSE $=.003, p=.31, \eta^{2}=$ .002 , but there was a significant difference on 1-location and on 5-location experimental trials, $F(1,60)=17.07, \mathrm{MSE}=.003, p<.0002, \eta^{2}=$ .03 , and $F(1,60)=9.60$, MSE $=.003, p<.003, \eta^{2}=.02$, respectively, with worse performance in the instructions-before condition than in the instructions-after condition. These differences were not predicted and the reason for them is not clear, but the important result for present purposes is that there was not a significant difference on the control trials.

\section{Target Checking}

The third question concerned whether participants performed worse on the 5-location experimental trials than on the 1-location experimental trials, which would provide evidence for target checking. A planned comparison was conducted to test this prediction. Trial type (1-location experimental, 5-location experimental) was the withinsubjects independent variable and RT task latency was the dependent variable. The comparison revealed significantly worse performance on the 5-location experimental trials than on the 1-location experimental trials, $F(1,94)=12.19, \mathrm{MSE}=21049.89, p<.0008, \eta^{2}=.11$, indicating that participants checked for the targets to a greater extent in the 5-location condition than in the 1-location condition. Neither RT task accuracy nor short-term memory accuracy was analyzed because neither omnibus ANOVA reported in the Task Interference section showed a significant effect.

\section{Prospective Memory}

Mean prospective memory appears in Table 1 for the mixed design conditions and in Table 2 for the within-subjects conditions. For the mixed design conditions, neither the effect of trial type, instruction time, or the interaction was significant (largest $F[1,30]=1.48, \mathrm{MSE}=.09, p=$ $.24, \eta^{2}=.02$ ). For the within-subjects conditions, prospective memory was not significantly different between the 1-location and the 5-location experimental trials, $F(1,47)=1.29, \mathrm{MSE}=.07, p=.27, \eta^{2}=.03$. 


\begin{tabular}{|c|c|c|c|}
\hline & $\begin{array}{c}\text { Control } \\
\text { trials }\end{array}$ & $\begin{array}{c}\text { 1-Location } \\
\text { experimental trials }\end{array}$ & $\begin{array}{c}\text { 5-Location } \\
\text { experimental trials }\end{array}$ \\
\hline & \multicolumn{3}{|c|}{ Instructions before control trials } \\
\hline \multirow[t]{2}{*}{$\begin{array}{l}\text { Reaction time task } \\
\text { latency }\end{array}$} & 1033 & 1048 & 1180 \\
\hline & (118) & (74) & (107) \\
\hline \multirow[t]{2}{*}{$\begin{array}{l}\text { Reaction time task } \\
\text { accuracy }\end{array}$} & .88 & .91 & .89 \\
\hline & $(.02)$ & $(.02)$ & $(.02)$ \\
\hline \multirow[t]{2}{*}{ Short-term memory } & .61 & .63 & .62 \\
\hline & $(.02)$ & $(.03)$ & $(.04)$ \\
\hline \multirow[t]{3}{*}{ Prospective memory } & & .69 & .75 \\
\hline & & $(.10)$ & $(.08)$ \\
\hline & \multicolumn{3}{|c|}{ Instructions after control trials } \\
\hline \multirow[t]{2}{*}{$\begin{array}{l}\text { Reaction time task } \\
\text { latency }\end{array}$} & 901 & 961 & 1103 \\
\hline & (54) & (64) & (88) \\
\hline \multirow[t]{2}{*}{$\begin{array}{l}\text { Reaction time task } \\
\text { accuracy }\end{array}$} & .88 & .92 & .90 \\
\hline & $(.03)$ & $(.02)$ & $(.03)$ \\
\hline \multirow[t]{2}{*}{ Short-term memory } & .63 & .71 & .68 \\
\hline & $(.03)$ & $(.03)$ & $(.04)$ \\
\hline \multirow[t]{2}{*}{ Prospective memory } & & .75 & .62 \\
\hline & & $(.08)$ & $(.11)$ \\
\hline
\end{tabular}

Note. Standard errors are in parentheses. Latencies are measured in milliseconds.

\section{DISCUSSION}

The results revealed task interference in that response times on experimental trials were significantly slower than on control trials. The results also provided evidence that task interference involves adopting a retrieval mode and checking for targets. Response times were slower on control trials when participants had already been instructed about the prospective memory task than when they had not yet been so instructed, indicating that participants adopted a retrieval mode when they were instructed about the prospective memory task. Response times were slower on the 5-location experimental trials than on the 1-location experimental trials, indicating that participants checked the environment (i.e., the short-term memory stimuli) for the targets to a greater extent in the 5-location condition than in the 1-location condition.

The prospective memory results did not (and were not expected to) parallel the task interference results. For the mixed-design conditions, participants in both the instructions-before and the instructions-after conditions should have adopted a retrieval mode on the experimental trials (i.e., it was only on the control trials where a difference was expected), and accordingly, prospective memory accuracy was similar between the groups. For the within-subjects conditions, participants checked for the targets to a greater extent in the 5-location condition than in the 1-location condition, but targets could have appeared in a greater number of locations in the 5-location condition than in the 1-location condition. So, the conditions were similar in terms of the extent of checking per possible target location, resulting in similar prospective memory accuracies.

As mentioned in the Introduction section, the REMO + TC view is not necessarily incompatible with other explanations of the task interference that occurs when a prospective memory task is embedded in an ongoing activity. Retrieval mode and target checking were initially proposed as an account of the mental processes underlying strategic monitoring (McDaniel \& Einstein, 2000), but the processes could just as easily be those that individuals engage in the course of allocating attentional resources from the ongoing activity and to the prospective memory task (Marsh et al., 2003). Moreover, there appears to be at least a surface similarity between the ideas of a preparatory attentional process (Smith, 2003) and being in a prospective memory retrieval mode, and between the ideas of a recognition memory process and target checking. Thus, the current study was not an attempt to legislate among these views but rather to evaluate a different behavioral paradigm for providing evidence for retrieval mode and target checking.

The results implicating a retrieval mode may also be at least partly caused by another process, rehearsing one or more elements of the prospective memory task (e.g., the target/s, the intended action/s, or both). In fact, many of the task interference findings in the literature may be at least partly caused by prospective memory rehearsal. Future work could be profitably directed at trying to disentangle rehearsal from the task interference cost that is attributed to a retrieval mode. One way could be to vary the difficulty of (retrospectively) remembering the prospective memory targets and to inspect ongoing activity performance in a situation where only a retrieval mode, not target checking, is operating. Any difference in the cost between the conditions would presumably be because of rehearsal. Another way could be to vary participant expectations about the difficulty of remembering the prospective memory targets (e.g., by mentioning an upcoming chance to rehearse) in a situation where only a retrieval mode, not target checking, is operating. Again, any difference in the cost between the conditions would presumably be because of rehearsal.

It seems easier to come up with ways to manipulate rehearsal than ways to manipulate a retrieval mode, perhaps because it seems easier to envision what goes on in mind during rehearsal than during a re-

\begin{tabular}{cccc}
\cline { 2 - 3 } & $\begin{array}{l}\text { TABLE 2. } \\
\text { Results for Within-Subjects Conditions }\end{array}$ \\
\hline & $\begin{array}{c}\text { Control } \\
\text { trials }\end{array}$ & $\begin{array}{c}\text { 1-Location } \\
\text { experimental trials }\end{array}$ & $\begin{array}{c}\text { 5-Location } \\
\text { experimental trials }\end{array}$ \\
\hline Reaction time task & 909 & 963 & 1067 \\
latency & & $(44)$ & $(55)$ \\
& $(49)$ & .91 & .90 \\
Reaction time task & .90 & $(.02)$ & $(.01)$ \\
accuracy & & .68 & .68 \\
Short-term memory & .70 & $(.02)$ & $(.02)$ \\
& $(.02)$ & .77 & .83 \\
Prospective memory & & $(.05)$ & $(.04)$ \\
& & &
\end{tabular}

Note. Standard errors are in parentheses. Latencies are measured in milliseconds. 
trieval mode. Further theoretical development of this construct would be useful in the effort to differentiate a retrieval mode from other demanding processes such as rehearsal. One useful and unique aspect of the current method is that the retrieval mode phase can be completely separated from the phase involving target checking, unlike with other methods wherein the presumed processes are intertwined across a set of trials. This allows variables to be manipulated for just the retrieval mode phase and thus can potentially be useful in trying to separate the retrieval mode from other processes that also depend on limited cognitive resources. This could also be useful for exploring the idea that the retrieval mode entails maintaining an increased level of activation of the contents of the intention (Guynn, 2003), as well as integrating the work on the retrieval mode with the work suggesting that task interference does not inevitably occur if a prospective memory target is not expected in a given context (e.g., Marsh, Hicks et al., 2006).

Researchers using physiological (functional neuroimaging, electrophysiological, and pupillometric) approaches have also interpreted results as providing evidence for a retrieval mode and target checking. This may actually be easier to do than with strictly behavioral approaches because there are established techniques for distinguishing between sustained (i.e., retrieval mode) and transient (i.e., target checking) processing in these physiological domains. For example, Burgess et al. (2001) and Moyes et al. (2019) interpreted their results in terms of a retrieval mode, and Bisiacchi et al. (2011) and Scolaro et al. (2014) interpreted their results in terms of target checking. Others have interpreted their results as providing support for both processes (Cona et al., 2012; Czernochowski et al., 2012; West et al., 2007; West et al., 2011). An even greater number of physiological studies have produced results that are consistent with the involvement of one or both processes, even though the researchers did not necessarily interpret their results in this way (for a brief review with regard to a retrieval mode, see Underwood et al., 2015). Another promising approach involves using different modeling techniques to uncover signatures or footprints of the two processes (e.g., Ball et al., 2015; Horn \& Bayen, 2015; Loft et al., 2014; Smith \& Bayen, 2004). Physiological approaches in conjunction with behavioral paradigms (including those using modeling approaches) such as the new one described herein may be especially useful for further investigations of the involvement of retrieval mode and target checking in prospective memory task interference.

\section{REFERENCES}

Anderson, N. D., Craik, F. I. M., \& Naveh-Benjamin, M. (1998). The attentional demands of encoding and retrieval in younger and older adults: 1. Evidence from divided attention costs. Psychology and Aging, 13, 405-423. doi: 10.1037/0882-7974.13.3.405 سلس

Ball, B. H., Brewer, G. A., Loft, S., \& Bowden, V. (2015). Uncovering continuous and transient monitoring profiles in event-based prospective memory. Psychonomic Bulletin \& Review, 22, 492-499. doi: 10.3758/s13423-014-0700-8

Ball, B. H., \& Bugg, J. M. (2018a). Aging and the strategic use of context to control prospective memory monitoring. Psychology and Aging, 33, 527-544. doi: 10.1037/pag0000247 المالس
Ball, B. H., \& Bugg, J. M. (2018b). Context cue focality influences strategic prospective memory monitoring. Psychonomic Bulletin \& Review, 25, 1405-1415. doi: 10.3758/s13423-018-1442-9 المبلسلسلس

Ball, B. H., Li, Y. P., \& Bugg, J. M. (2020). Aging and strategic prospective memory monitoring. Memory \& Cognition, 48, 370-389. doi: 10.3758/s13421-019-00976-8 المالسلس

Bisiacchi, P. S., Cona, G., Schiff, S., \& Basso, D. (2011). Modulation of a fronto-parietal network in event-based prospective memory: An rTMS study. Neuropsychologia, 49, 2225-2232. doi: 10.1016/j. neuropsychologia.2011.05.007 السلسلس

Bugg, J. M., \& Ball, B. H. (2017). The strategic control of prospective memory monitoring in response to complex and probabilistic contextual cues. Memory \& Cognition, 45, 755-775. doi: 10.3758/

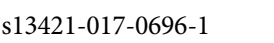

Burgess, P. W., Quayle, A., \& Frith, C. D. (2001). Brain regions involved in prospective memory as determined by positron emission tomography. Neuropsychologia, 39, 545-555. doi: 10.1016/S00283932(00)00149-4 السلسلسلس

Cohen, A.-L., Jaudas, A., Hirschhorn, E., Sobin, Y., \& Gollwitzer, P. (2012). The specificity of prospective memory costs. Memory, 20, 848-864. doi: 10.1080/09658211.2012.710637 الس

Cona, G., Arcara, G., Tarantino, V., \& Bisiacchi, P. S. (2012). Electrophysiological correlates of strategic monitoring in eventbased and time-based prospective memory. PLOS One, 7, e31659 doi: 10.1371/journal.pone.0031659 السلسلسلة

Craik, F. I. M., Govoni, R., Naveh-Benjamin, M., \& Anderson, N. D. (1996). The effects of divided attention on encoding and retrieval processes in human memory. Journal of Experimental Psychology: General, 125, 159-180. doi: 10.1037/0096-3445.125.2.159 المسلسلس

Czernochowski, D., Horn, S., \& Bayen, U. J. (2012). Does frequency matter? ERP and behavioral correlates of monitoring for rare and frequent prospective memory targets. Neuropsychologia, 50, 67-76.

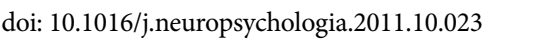

Einstein, G. O., \& McDaniel, M. A. (1990). Normal aging and prospective memory. Journal of Experimental Psychology: Learning, Memory,

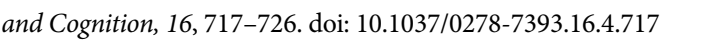

Einstein, G. O., McDaniel, M. A., Thomas, R., Mayfield, S., Shank, H., Morrisette, N., \& Breneiser, J. (2005). Multiple processes in prospective memory retrieval: Factors determining monitoring versus spontaneous retrieval. Journal of Experimental Psychology: General, 134, 327-342. doi: 10.1037/0096-3445.134.3.327 الس سلس

Guynn, M. J. (2003). A two-process model of strategic monitoring in event-based prospective memory: Activation/retrieval mode and checking. International Journal of Psychology, 38, 245-256. doi: 10.1080/00207590344000178 إس

Guynn, M. J. (2008). Theory of strategic monitoring: Instantiating a retrieval mode and periodic target checking. In M. Kliegel, M. A. McDaniel, \& G. O. Einstein (Eds.), Prospective memory: Cognitive, neuroscience, developmental, and applied perspectives. Taylor and Francis.

Guynn, M. J., \& Underwood, A. G. (2014, May). New evidence for retrieval mode + target checking in task interference. [Poster presen- 
tation]. The 4th International Conference on Prospective Memory, Naples, Italy.

Hicks, J. L., Marsh, R. L., \& Cook, G. I. (2005). Task interference in time-based, event-based, and dual intention prospective memory conditions. Journal of Memory and Language, 53, 430-444. doi: 10.1016/j.jml.2005.04.001 المسلسلس c

Horn, S. S., \& Bayen, U. J. (2015). Modeling criterion shifts and target checking in prospective memory monitoring. Journal of Experimental Psychology: Learning, Memory, and Cognition, 41, 95-117. doi: 10.1037/a0037676 سلسلسلس

Kliegel, M., Martin, M., McDaniel, M. A., \& Einstein, G. O. (2001). Varying the importance of a prospective memory task: Differential effects across time- and event-based prospective memory. Memory, 9, 1-11. doi: 10.1080/09658210042000003 السلسلس

Kliegel, M., Martin, M., McDaniel, M. A., \& Einstein, G. O. (2004). Importance effects on performance in event-based prospective memory tasks. Memory, 12, 553-561. doi: 10.1080/09658210344000099 الفيلسل|

Loft, S., Bowden, V. K., Ball, B. H., \& Brewer, G. A. (2014). Fitting an ex-Gaussian function to examine costs in event-based prospective memory: Evidence for a continuous monitoring profile. Acta Psychologica, 152, 177-182. doi: 10.1016/j.actpsy.2014.08.010 المالسلسليا Acta

Lourenço, J. S., \& Maylor, E. A. (2014). Is it relevant? Influence of trial manipulations of prospective memory context on task interference. The Quarterly Journal of Experimental Psychology, 67, 687-702. doi: 10.1080/17470218.2013.826257 سلس

Lourenço, J. S., White, K., \& Maylor, E. A. (2013). Target context specification can reduce costs in nonfocal prospective memory. Journal of Experimental Psychology: Learning, Memory, and Cognition, 39,

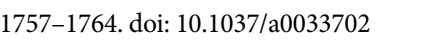

Marsh, R. L., Cook, G. I., \& Hicks, J. L. (2006). Task interference from event-based intentions can be material specific. Memory \& Cognition, 34, 1636-1643. doi: 10.3758/BF03195926 المالسلسلبا

Marsh, R. L., Hicks, J. L., \& Cook, G. I. (2006). Task interference from prospective memories covaries with contextual associations of fulfilling them. Memory \& Cognition, 34, 1037-1045. doi: 10.3758/ BF03193250 سلس

Marsh, R. L., Hicks, J. L., Cook, G. I., Hansen, J. S., \& Pallos, A. L. (2003). Interference to ongoing activities covaries with the characteristics of an event-based intention. Journal of Experimental Psychology: Learning, Memory, and Cognition, 29, 861-870. doi: 10.1037/02787393.29.5.861 السلسلس

McDaniel, M. A., \& Einstein, G. O. (2000). Strategic and automatic processes in prospective memory retrieval: A multiprocess framework. Applied Cognitive Psychology, 14, S127-S144. doi: 10.1002/acp.775 المالسلسل|

McDaniel, M. A., Guynn, M. J., Einstein, G. O., \& Breneiser, J. (2004). Cue-focused and reflexive-associative processes in prospective memory retrieval. Journal of Experimental Psychology: Learning, Memory, and Cognition, 30, 605-614. doi: 10.1037/0278-7393.30.3.605 اليلسلس

Moyes, J., Sari-Sarraf, N., \& Gilbert, S. J. (2019). Characterizing monitoring processes in event-based prospective memory: Evidence from pupillometry. Cognition, 184, 83-95. doi: 10.1016/j.cogni-

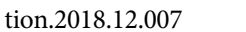

Navon, D., \& Gopher, D. (1979). On the economy of the human-processing system. Psychological Review, 86, 214-255. doi: 10.1037/0033295X.86.3.214 الس

Reitman, J. S. (1971). Mechanisms of forgetting in short-term memory. Cognitive Psychology, 2, 185-195. doi: 10.1016/00100285(71)90008-9 الم

Reitman, J. S. (1974). Without surreptitious rehearsal, information in short-term memory decays. Journal of Verbal Learning and Verbal Behavior, 13, 365-377. doi: 10.1016/S0022-5371(74)80015-0 البلسلسلكا

Scolaro, A., West, R., \& Cohen, A.-L. (2014). The ERP correlates of target checking are dependent upon the defining features of the prospective memory cues. International Journal of Psychophysiology, 93, 298-304. doi: 10.1016/j.ijpsycho.2014.06.008 السلسلس

Scullin, M. K., McDaniel, M. A., \& Shelton, J. T. (2013). The dynamic multiprocess framework: Evidence from prospective memory with contextual variability. Cognitive Psychology, 67, 55-71. doi: 10.1016/j. cogpsych.2013.07.001 المالسلسلس

Scullin, M. K., McDaniel, M. A., Shelton, J. T., \& Lee, J. H. (2010). Focal/ nonfocal cue effects in prospective memory: Monitoring difficulty or different retrieval processes? Journal of Experimental Psychology: Learning, Memory, and Cognition, 36, 736-749. doi: 10.1037/ a0018971 سلس الس

Smith, R. E. (2003). The cost of remembering to remember in eventbased prospective memory: Investigating the capacity demands of delayed intention performance. Journal of Experimental Psychology: Learning, Memory, and Cognition, 29, 347-361. doi: 10.1037/02787393.29.3.347 السلسلس

Smith, R. E., \& Bayen, U. J. (2004). A multinomial model of eventbased prospective memory. Journal of Experimental Psychology: Learning, Memory, and Cognition, 30, 756-777. doi: 10.1037/02787393.30.4.756 السلسلس

Smith, R. E., Hunt, R. R., \& Murray, A. E. (2017). Prospective memory in context: Moving through a familiar space. Journal of Experimental Psychology: Learning, Memory, and Cognition, 43, 189-204.

Toglia, M. P., \& Battig, W. F. (1978). Handbook of semantic word norms. Erlbaum.

Tulving, E. (1983). Elements of episodic memory. Oxford University Press.

Underwood, A. G., Guynn, M. J., \& Cohen, A.-L. (2015). The future orientation of past memory: The role of BA 10 in prospective and retrospective retrieval modes. Frontiers in Human Neuroscience, 9: 668. doi: 10.3389/fnhum.2015.00668 الم

West, R., McNerney, M. W., \& Travers, S. (2007). Gone but not forgotten: The effects of cancelled intentions on the neural correlates of prospective memory. International Journal of Psychophysiology, 64, 215-225. doi: 10.1016/j.ijpsycho.2006.09.004 الم السلسلس

West, R., Scolaro, A. J., \& Bailey, K. (2011). When goals collide: The interaction between prospective memory and task switching. Canadian Journal of Experimental Psychology, 65, 38-47. doi:

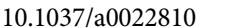

RECEIVED 02.12.2019| ACCEPTED 20.04.2021 


\section{APPENDIX A}

Conditions exploring target checking:

Within-group manipulation of trial type

\begin{tabular}{lcccc}
\hline & First block & Second block & Third block & \\
\hline PM instructions & CON & EXP-1 & EXP-5 & $\boldsymbol{n}=\mathbf{8}$ \\
PM instructions & CON & EXP-5 & EXP-1 & $\boldsymbol{n}=\mathbf{8}$ \\
PM instructions & EXP-1 & CON & EXP-5 & $n=8$ \\
PM instructions & EXP-1 & EXP-5 & CON & $n=8$ \\
PM instructions & EXP-5 & CON & EXP-1 & $n=8$ \\
PM instructions & EXP-5 & EXP-1 & CON & $n=8$ \\
\hline
\end{tabular}

Note. CON = control trials; EXP-1 = 1-location experimental trials; EXP-5 $=5$-location experimental trials. The conditions in bold are duplicated in Appendix B.

\section{APPENDIX B}

Conditions exploring retrieval mode:

Between-group manipulation of prospective memory instruction location

\begin{tabular}{|c|c|c|c|c|}
\hline \multicolumn{5}{|c|}{ PM instructions before control trials } \\
\hline & First block & Second block & Third block & \\
\hline PM instructions & CON & EXP-1 & EXP-5 & $n=8$ \\
\hline PM instructions & CON & EXP-5 & EXP-1 & $n=8$ \\
\hline \multicolumn{5}{|c|}{ PM instructions after control trials } \\
\hline First block & & Second block & Third block & \\
\hline $\mathrm{CON}$ & PM instructions & EXP-1 & EXP-5 & $n=8$ \\
\hline $\mathrm{CON}$ & PM instructions & EXP-5 & EXP1 & $n=8$ \\
\hline
\end{tabular}

Note. $\mathrm{CON}=$ control trials; EXP-1 = 1-location experimental trials; EXP-5 = 5-location experimental trials. The conditions in bold are duplicated in Appendix A. 